\title{
Effects of in vitro Culture Period of Reconstructed Embryos and Genetic Background of Feeder Cells on Establishment of Embryonic Stem Cells Derived from Somatic Cell Nuclear Transfer Blastocysts in Pigs
}

\author{
$\mathrm{Na}$ Rae Han ${ }^{1}$, Song Baek ${ }^{1}$, Yongjin Lee ${ }^{2,3}$, Joohyeong Lee ${ }^{4}$, Jung Im Yun ${ }^{5}$, Eunsong Lee ${ }^{2}$ \\ and Seung Tae Lee ${ }^{1,5,6, *}$ \\ ${ }^{1}$ Department of Animal Life Science, Kangwon National University, Chuncheon 24341, Korea \\ ${ }^{2}$ College of Veterinary Medicine, Kangwon National University, Chuncheon 24341, Korea \\ ${ }^{3}$ Optipharm Inc., Cheongju 28158, Korea \\ ${ }^{4}$ Institute of Veterinary Medicine, Kangwon National University, Chuncheon 24341, Korea \\ ${ }^{5}$ KustoGen Inc., Chuncheon 24341, Korea \\ ${ }^{6}$ Department of Applied Animal Science, Kangwon National University, Chuncheon 24341, Korea
}

Received March 13, 2020

Revised March 24, 2020

Accepted March 25, 2020

\section{*Correspondence}

Seung Tae Lee

E-mail: stlee76@kangwon.ac.kr

ORCID

https://orcid.org/0000-0002-8952-3881

\begin{abstract}
The establishment of porcine embryonic stem cells (ESCs) from porcine somatic cell nuclear transfer (SCNT) blastocysts is influenced by in vitro culture day of porcine reconstructed embryo and feeder cell type. Therefore, the objective of the present study was to determine the optimal in vitro culture period for reconstructed porcine SCNT embryos and mouse embryonic fibroblast (MEF) feeder cell type for enhancing colony formation efficiency from the inner cell mass (ICM) of porcine SCNT blastocysts and their outgrowth. As the results, porcine SCNT blastocysts produced through in vitro culture of the reconstructed embryos for 8 days showed significantly increased efficiency in the formation of colonies, compared to those for 7 days. Moreover, MEF feeder cells derived from outbred ICR mice showed numerically the highest efficiency of colony formation in blastocysts produced through in vitro culture of porcine SCNT embryos for 8 days and porcine ESCs with typical ESC morphology were maintained more successfully over Passage 2 on outbred ICR mice-derived MEF feeder cells than on MEF feeder cells derived from inbred C57BL/ 6 and hybrid B6CBAF1 mice. Overall, the harmonization of porcine SCNT blastocysts produced through in vitro culture of the reconstructed embryos for 8 days and MEF feeder cells derived from outbred ICR mice will greatly contribute to the successful establishment of ESCs derived from porcine SCNT blastocysts.
\end{abstract}

Keywords: embryonic stem cells, genetic background of feeder cells, in-vitro culture period, pig, somatic cell nuclear transfer

\section{INTRODUCTION}

The pigs are considered as useful biomedical models and embryonic stem cells (ESCs) can self-renew and differentiate into three germ layers (Cha et al., 2018; Zhang et al., 2019). Therefore, ESCs derived from the inner cell 
mass (ICM) of porcine blastocysts have been applied in numerous applications, such as drug screening, cell therapy, and transgenic pig production (Kim and Hyun, 2016; Baek et al., 2017; Choi et al., 2019). To date, researchers have been tried to establish ESCs derived from porcine blastocysts for active uses of ESCs and efforts have been mainly performed using blastocysts produced in vivo due to higher quality of blastocysts produced in vivo than those of produced in vitro (Son et al., 2009; Nakamura et al., 2017; Lee et al., 2018). However, procedures for in vivo generation of porcine blastocyst are laborious, costly, and time-consuming (Han et al., 2019). Therefore, for establishment of porcine ESCs, the usages of in vitro produced porcine blastocysts through in vitro fertilization (IVF) or somatic cell nuclear transfer (SCNT) have been preferred to overcome obstacles which encountered during the production of in vivo-derived blastocysts (Hou et al., 2016). Despite these efforts, the establishment efficiency of ESCs derived from blastocysts generated from in vitro produced porcine embryos remains very low.

Various factors, including blastocyst age, feeder cell type, ICM isolation method, and culture medium, have been examined to improve ESC establishment methods (Brevini et al., 2007; Vackova et al., 2007; Haraguchi et al., 2012). A previous study reported that ICM derived from blastocysts cultured in vitro for 7 days maintained pluripotency (Tan et al., 2012). However, late growth and degeneration were observed in colonies derived from ICM of early-stage blastocyst (Chen et al., 1999). By contrast, ICM derived from blastocysts cultured in vitro for longer than 9 days did not exhibit pluripotency (Tan et al., 2012), and rapid differentiation was observed in ICM of late-stage blastocyst (Wianny et al., 1997). These results suggest that an appropriate blastocyst stage should be determined for the successful establishment of ESC.

Feeder cells are routinely used as an attachment matrix for ESC establishment and maintenance (Llames et al., 2015; Siriboon et al., 2015) because they secrete unknown factors that support proliferation and inhibit differentiation (Yang et al., 2016; Li et al., 2017). Because these unknown factors secreted from feeder cells differ according to the genetic background of feeder cells (Talbot et al., 2012), preferred genetic background of feeder cells is dependent on ESC lines (Brevini et al., 2012; Park et al., 2015; Yang et al., 2016). Therefore, optimization of genetic background of feeder cell is also essential for suc- cessful establishment of ESC.

Based on these knowledge, determination of appropriate blastocyst stage and genetic background of feeder cells is required for enhancing establishment efficiency of ESCs derived from porcine SCNT blastocysts. The objective of the present study was to establish a culture system by determining the appropriate blastocyst stage and genetic background of feeder cell to enhance the establishment efficiency of ESCs derived from porcine SCNT blastocysts. For these, attachment to feeder cells and colony formation were monitored in ICM of porcine SCNT blastocysts cultured in vitro for 7 or 8 days. Porcine SCNT blastocysts showing the highest feeder cell attachment and colony formation efficiency were then cultured in mouse embryonic fibroblast (MEF) feeder cells derived from three mouse strains, and the optimal strain of MEF feeder cell was determined by comparing the efficiencies in the attachment of porcine SCNT blastocysts to feeder cells and the formation of colony derived from ICM of porcine SCNT blastocysts.

\section{MATERIALS AND METHODS}

\section{Animals}

As mouse embryonic fibroblast (MEF) donors, fetuses derived from 13.5-day pregnant female ICR (DBL, Eumseong, Korea) crossed with male ICR (DBL), C57BL/6 (Nara Biotech, Seoul, Korea) crossed with male C57BL/6 (Nara Biotech), and C57BL/6 (Koatech, Pyongtaek, Korea) crossed with male CBA (Koatech) mice were used. Porcine ovaries were obtained from prepubertal gilts at a local abattoir. All animal housing, handling, and experimental procedures were approved by the Institutional Animal Care and Use Committee (IACUC) of Kangwon National University (IACUC approval no. KW-170131-1) and conducted according to the Animal Care and Use Guidelines of Kangwon National University.

\section{Retrieval of cumulus-oocyte complexes (COCs) and in vitro maturation (IVM)}

In the ovaries, COCs were aspirated from superficial follicles using an 18-guage needle. Next, COCs with multiple layers of unexpanded cumulus cells were justly selected and washed three times in HEPES-buffered Tyrode's medium (TLH) supplemented with $0.05 \%(w / v)$ polyvinyl alcohol (PVA; Sigma-Aldrich, St. Louis, MO). Culture of the 
washed COCs in a four-well culture dish (Nunc, Roskilde, Denmark) containing $500 \mu \mathrm{L}$ of IVM medium consisting of medium-199 (M-199; Invitrogen, Carlsbad, CA) supplemented with $10 \%(\mathrm{v} / \mathrm{v})$ porcine follicular fluid, $1 \mu \mathrm{g} /$ $\mathrm{mL}$ insulin (Sigma-Aldrich), $10 \mathrm{ng} / \mathrm{mL}$ epidermal growth factor (EGF, Sigma-Aldrich), $0.6 \mathrm{mM}$ cysteine (SigmaAldrich), $0.91 \mathrm{mM}$ pyruvate (Sigma-Aldrich), $75 \mu \mathrm{g} / \mathrm{mL}$ kanamycin (Sigma-Aldrich), $10 \mathrm{IU} / \mathrm{mL}$ human chorionic gonadotropin (hCG; Intervet International BV, Boxmeer, Holland) and $80 \mu \mathrm{g} / \mathrm{mL}$ follicle-stimulating hormone (FSH; Antrin R-10, Kyoritsu Seiyaku, Tokyo, Japan) was conducted for $22 \mathrm{~h}$ at $39^{\circ} \mathrm{C}$ with $5 \% \mathrm{CO}_{2}$. Subsequently, the in vitro maturated COCs were washed three times with hormone-free IVM medium and additionally cultured in hormone-free IVM medium for $20 \mathrm{~h}$ at $39^{\circ} \mathrm{C}$ with $5 \% \mathrm{CO}_{2}$.

\section{Preparation of donor cells}

As donor cells, a newborn piglet-derived fetal fibroblasts were cultured in Dulbecco's modified Eagle's medium (DMEM) with the nutrient mixture F-12 (Invitrogen) and $15 \%(\mathrm{v} / \mathrm{v})$ fetal bovine serum (FBS, Invitrogen) until a complete monolayer of cells. Subsequently, the donor cells were synchronized at the G0/G1 stage of the cell cycle by inducing contact inhibition for 72-96 h and dissociated with $0.05 \%$ trypsin-EDTA (Invitrogen). The dissociated donor cells were resuspended in TLH supplemented with $0.4 \%(\mathrm{w} / \mathrm{v})$ bovine serum albumin (BSA; Sigma-Aldrich) before nuclear transfer.

\section{Generation of somatic cell nuclear transfer (SCNT) embryos}

After IVM, cumulus cells were removed from COCs by repeated pipetting in TLH supplemented with $0.4 \%(\mathrm{w} / \mathrm{v})$ BSA and $0.1 \%(w / v)$ hyaluronidase (Sigma-Aldrich). Subsequently, the cumulus cell-free oocytes were stained in calcium-free TLH supplemented with $0.4 \%$ (w/v) BSA and 5 $\mu \mathrm{g} / \mathrm{mL}$ Hoechst 33342 (Sigma-Aldrich) for $15 \mathrm{~min}$ at $39^{\circ} \mathrm{C}$ with $5 \% \mathrm{CO}_{2}$ and washed twice with calcium-free TLH supplemented with $0.4 \%(\mathrm{w} / \mathrm{v})$ BSA. The washed oocytes were transferred to a drop of calcium-free TLH supplemented with $0.4 \%(\mathrm{w} / \mathrm{v}) \mathrm{BSA}$ and $5 \mu \mathrm{g} / \mathrm{mL}$ cytochalasin B (Sigma-Aldrich) under mineral oil (Sigma-Aldrich). Next, the first polar body and metaphase II (MII) chromosomes of oocytes were aspirated using a $17 \mu \mathrm{m}$ beveled pipette (Humagen, Charlottesville, VA) under an epifluorescence microscope (IX73; Olympus, Tokyo, Japan) for generation of enucleated oocytes, and a single donor cell was inserted into the perivitelline space of each enucleated oocyte. After then, oocyte-cell couplets were placed on a fusion electrode chamber (NepaGene, Chiba, Japan) overlaid with $280 \mathrm{mM}$ mannitol solution (Sigma-Aldrich) supplemented with $1 \mu \mathrm{M} \mathrm{CaCl}_{2}$ (Wako pure chemical industries, Osaka, Japan) and $50 \mu \mathrm{M} \mathrm{MgCl}_{2}$ (Wako pure chemical industries) and exposed to an alternating current of $2 \mathrm{~V}$ cycling at $1 \mathrm{MHz}$ for $2 \mathrm{sec}$, and two pulses of $175 \mathrm{~V} / \mathrm{mm}$ direct current (DC) for $30 \mu$ s using a cell fusion generator (LF101; NepaGene). Successful fusion of oocyte-cell couplets was investigated under a stereomicroscope and incubation of fused oocyte-cell couplets was conducted for $30 \mathrm{~min}$ in calcium-free TLH supplemented with $0.4 \%$ $(w / v)$ BSA. After 30 min of incubation, SCNT oocytes were activated by exposing to two DC pulse of $120 \mathrm{~V} / \mathrm{min}$ for $60 \mu \mathrm{s}$ in a $280 \mathrm{mM}$ mannitol solution supplemented 0.1 $\mathrm{mM} \mathrm{CaCl}{ }_{2}$ and $0.05 \mathrm{mM} \mathrm{MgCl}_{2}$.

\section{In vitro culture of SCNT embryos}

For culturing SCNT embryos, $0.34 \mathrm{mM}$ trisodium citrate (Sigma-Aldrich), $2.77 \mathrm{mM}$ myo-inositol (Sigma-Aldrich), and $10 \mu \mathrm{M} \beta$-mercaptoethanol (Sigma-Aldrich) were supplemented into porcine zygote medium (PZM)- 5 described previously (Yamanaka et al., 2009) (herein referred to as the modified PZM-5). Moreover, 10\% (v/v) FBS was supplemented into the modified PZM-5 (herein referred to as the PZM-5F). The electrically activated SCNT embryos were incubated for $4 \mathrm{~h}$ in the modified PZM- 5 supplemented with $0.4 \mu \mathrm{g} / \mathrm{mL}$ demecolcine (Sigma-Aldrich) and 2 mM 6-dimethylaminopurine (6-DMAP; Sigma-Aldrich). After washing with the modified PZM-5, the washed SCNT embryos were cultured for $96 \mathrm{~h}$ in $30 \mu \mathrm{L}$ of the modified PZM-5 droplets (10-15 embryos/droplet) covered with mineral oil at $39^{\circ} \mathrm{C}$ in $5 \% \mathrm{CO}_{2}, 5 \% \mathrm{O}_{2}$, and $90 \% \mathrm{~N}_{2}$ and then the SCNT embryos were additionally cultured for 72 h or $96 \mathrm{~h}$ in $30 \mu \mathrm{L}$ of the modified PZM-5F droplets (1015 embryos/droplet) covered with mineral oil at $39^{\circ} \mathrm{C}$ in $5 \% \mathrm{CO}_{2}, 5 \% \mathrm{O}_{2}$, and $90 \% \mathrm{~N}_{2}$. Subsequently, the produced SCNT blastocysts were allocated to the following experiments.

\section{Preparation of MEF feeder cells}

Uterus obtained from pregnant mice at embryonic day 13.5 were transferred to a Petri dish containing Dulbecco's phosphate-buffered saline (DPBS; Welgene Inc., Daegu, 
Korea). Organs of fetuses were discarded, and the remainder of fetal tissues were minced with razor blades. Then, the minced tissues were digested with $0.25 \%$ trypsin-EDTA (Welgene) for $10 \mathrm{~min}$ at $37^{\circ} \mathrm{C}$. Non-digested fibroblasts were discarded using 70- $\mu \mathrm{m}$ nylon mesh (SPL Life Sciences, Pocheon, Korea), and the digested MEFs were washed with MEF culture medium consisting of DMEM (Welgene) supplemented with $10 \%(\mathrm{v} / \mathrm{v})$ heat-inactivated FBS (Welgene) and $1 \%(\mathrm{v} / \mathrm{v})$ antibiotic-antimycotic solution (Welgene). Subsequently, the purified MEFs were cultured in MEF culture medium at $37^{\circ} \mathrm{C}$ under $5 \% \mathrm{CO}_{2}$, until $90 \%$ confluency, and the fresh culture medium was changed at 2-day intervals. To inhibit proliferation of MEFs, confluent MEFs at Passage 1 were inactivated in MEF culture medium containing $10 \mu \mathrm{g} / \mathrm{mL}$ mitomycin C (Sigma-Aldrich) for $3 \mathrm{~h}$ at $37^{\circ} \mathrm{C}$ and detached with $0.05 \%$ trypsin-EDTA (Welgene). The inactivated MEFs were plated in four-well culture plate (SPL Life Sciences) coated with $0.1 \%(w / v)$ gelatin (Sigma-Aldrich) and provided as a feeder layer.

\section{In vitro outgrowth of ICM of SCNT blastocysts}

The three types of culture medium were used to induce formation of colonies derived from ICM of SCNT blastocysts. Alpha-MEM-based medium consists of $\alpha$-MEM medium (Gibco, Carlsbad, CA) supplemented with 10\% (v/ v) knockout serum replacement (KSR; Invitrogen), 0.05 mM $\beta$-mercaptoethanol (Gibco), 1\% (v/v) nonessential amino acids (NEAA; Gibco), 40 ng/mL EGF (PeproTech, Inc., Rocky Hill, NJ), $10 \mu \mathrm{L} / \mathrm{mL} 100 \mathrm{x}$ insulin-transferrinselenium (ITS; Gibco), $1000 \mathrm{U} / \mathrm{mL}$ mouse leukemia inhibitory factor (mLIF; Chemicon International, Inc., Temecula, CA), $20 \mathrm{ng} / \mathrm{mL}$ basic fibroblast growth factor (bFGF; PeproTech, Inc.,), and 1\% (v/v) antibiotic-antimycotic solution. DMEM/Ham's F-10-based medium consists of 1:1 low-glucose DMEM (LG-DMEM; Welgene):Ham's F-10 (Gibco) medium supplemented with 15\% (v/v) heat-inactivated ES cell-screened FBS (Hyclone, Logan, UT), $0.2 \mathrm{mM}$ $\beta$-mercaptoethanol, $1 \%$ (v/v) NEAA, $20 \mathrm{ng} / \mathrm{mL}$ bFGF and $1 \%(\mathrm{v} / \mathrm{v})$ antibiotic-antimycotic solution. Mixture medium consists of a 50:50 mixture of $\mu$-MEM-based medium and DMEM/Ham's F-10-based medium.

To induce colony formation derived from ICM of porcine SCNT blastocysts, the zona pellucida (ZP) of SCNT blastocysts was mechanically removed by insulin syringe under a stereomicroscope (Olympus), and ZP-free SCNT blastocysts were cultured for 7 days on mitotically in- activated MEF feeder cells derived from fetuses of outbred ICR, inbred C57BL/6, or hybrid B6CBAF1 mice in $\alpha$-MEM-based medium at $37^{\circ} \mathrm{C}$ under an atmosphere of $5 \% \mathrm{CO}_{2}$ in air (Passage 0). The fresh culture medium was replaced daily. Subsequently, the outgrown ICM were dissociated mechanically using glass capillary pipettes, and the detached clumps were reseeded and cultured on fresh mitotically inactivated MEF feeder cells for 4 days in mixture medium at $37^{\circ} \mathrm{C}$ under an atmosphere of $5 \% \mathrm{CO}_{2}$ in air (Passage 1). Under the same condition as Passage 1 , the following subculture was conducted. Formation of colonies from ICM of SCNT blastocysts and morphology of colonies were observed under an inverted microscope (CKX41; Olympus).

\section{Statistical analysis}

The Statistical Analysis System (SAS) software (SAS Institute Inc, Cary, NY) was used for analyzing all numerical data in each parameter. Comparisons among treatment groups were conducted using a generalized linear model (PROC-GLM) in the SAS package. The less than 0.05 of $p$ value was regarded as a statistically significant difference.

\section{RESULTS}

Firstly, to determine the optimal embryo culture period to produce porcine SCNT blastocysts leading effectively to formation of colonies from ICM of blastocysts, the reconstructed porcine SCNT embryos were in vitro cultured for 7 or 8 days. Then, SCNT blastocysts were cultured for 7 days on MEF feeder cells derived from ICR mice. As shown in Table 1, in vitro culture period of reconstructed embryos had no significant effect on attachment efficiency of porcine SCNT blastocyst. However, colony formation was significantly improved in the ICM of porcine SCNT blastocysts cultured in vitro for 8 days, compared to those cultured for 7 days.

Subsequently, to elucidate the effects of MEF feeder cell type on the formation and outgrowth of colonies derived from the ICM of porcine SCNT blastocysts, porcine SCNT blastocysts generated through in vitro embryo culture for 8 days were further cultured for 7 days on MEF feeder cells derived from outbred ICR, inbred C57BL/6, and hybrid B6CBAF1 mice, respectively. As the results, numerically the highest efficiency of attachment and colony formation was observed in outbred ICR mice (Table 2). 
Table 1. Comparison of attachment to feeder cells and formation of colonies between blastocysts produced by in vitro culture of porcine SCNT embryos for 7 and 8 days

\begin{tabular}{cccc}
\hline $\begin{array}{c}\text { In-vitro culture day of } \\
\text { porcine SCNT embryos }\end{array}$ & $\begin{array}{c}\text { No. of SCNT } \\
\text { blastocysts seeded }\end{array}$ & $\begin{array}{c}\text { No. (\%) })^{\mathrm{c}} \text { of } \\
\text { attached to feeder cells }\end{array}$ & $\begin{array}{c}\text { Colonies formed } \\
\text { successfully from ICM }\end{array}$ \\
\hline 7 days $^{\mathrm{a}}$ & 62 & $46(74.19)$ & $23(37.10)^{\mathrm{d}}$ \\
8 days $^{\mathrm{b}}$ & 56 & $40(71.43)$ & $31(55.36)^{\mathrm{e}}$ \\
\hline
\end{tabular}

Model effects of treatments in each parameter, which is indicated as the $p$ value, were 0.7385 and 0.0473 in the number of blastocysts attached to feeder cells and the number of colonies formed successfully from ICM.

PZM: Porcine zygote medium, ICM: Inner cell mass.

${ }^{a}$ SCNT blastocysts were generated through sequential culture of porcine SCNT embryos for $96 \mathrm{~h}$ in the modified PZM-5 and for $72 \mathrm{~h}$ in the PZM-5F. ${ }^{b}$ SCNT blastocysts were generated through sequential culture of porcine SCNT embryos for $96 \mathrm{~h}$ in the modified PZM-5 and for $96 \mathrm{~h}$ in the PZM-5F. Zona pellucida of generated blastocysts were removed mechanically and subsequent cultured for 7 days on mitotically inactivated MEF feeder cells derived from outbred ICR mice in $\alpha$-MEM-based medium.

'Percentage of the number of SCNT blastocysts seeded.

d,e Values in the same column with different superscript letters are significantly different, $p<0.05$.

Table 2. Determination of genetic background of feeder cells stimulating in-vitro maintenance of colonies formed from ICM of blastocysts produced through in vitro culture of porcine SCNT embryos for 8 days

\begin{tabular}{ccccc}
\hline \multirow{2}{*}{$\begin{array}{c}\text { Types of genetic } \\
\text { background of feeder cells }\end{array}$} & $\begin{array}{c}\text { No. of SCNT } \\
\text { blastocysts seeded }\end{array}$ & $\begin{array}{c}\text { NCNT blastocysts } \\
\text { attached to feeder cells }\end{array}$ & $\begin{array}{c}\text { Colonies formed } \\
\text { successfully from ICM }\end{array}$ & $\begin{array}{c}\text { Colonies cultured } \\
\text { over Passage 2 }\end{array}$ \\
\hline ICR & 90 & $57(63.33)$ & $26(28.89)$ & $3(3.33)$ \\
C57BL/6 & 72 & $44(61.11)$ & $18(25.00)$ & $0(0.00)$ \\
B6CBAF1 & 71 & $43(60.56)$ & $20(28.17)$ & $0(0.00)$ \\
\hline
\end{tabular}

Model effects of treatments in each parameter, which is indicated as the $p$ value, were $0.9286,0.8501$ and 0.09 in the number of blastocysts attached to feeder cells, the number of colonies formed successfully from ICM, and the number of colonies cultured over Passage 2.

PZM: Porcine zygote medium, ICM: Inner cell mass.

Zona pellucida of SCNT blastocysts generated through sequential culture of porcine SCNT embryos for $96 \mathrm{~h}$ in the modified PZM-5 and for $96 \mathrm{~h}$ in the PZM$5 F$ were removed mechanically and subsequent cultured for 7 days on mitotically inactivated MEFs feeder cells derived from outbred ICR, inbred C57BL/6, and hybrid B6CBAF1 mice in $\alpha$-MEM-based medium.

aPercentage of the number of SCNT blastocysts seeded.

Notably, among 26 colonies formed from the ICM of porcine SCNT blastocysts cultured on MEF feeder cells derived from outbred ICR mice, three colonies with well-defined boundaries and flattened morphology (Fig. 1) were successfully outgrown and consistently maintained over Passage 2 (Table 2). However, long-term maintenance of colonies outgrown from the ICM of porcine SCNT blastocyst was unsuccessful on MEF feeder cells derived from outbred ICR mice. On the other hand, outgrown colony maintained over Passage 2 was not observed from the ICM of porcine SCNT blastocysts cultured on MEF feeder cells derived from inbred $\mathrm{C} 57 \mathrm{BL} / 6$ or hybrid B6CBAF1 mice (Table 2). Thus, MEF feeder cells derived from outbred ICR mice were optimal for the formation and outgrowth of colonies derived from the ICM of porcine SCNT blastocysts.

Thus, the formation and outgrowth of colonies derived from the ICM of porcine SCNT blastocysts can be effectively stimulated by in vitro culture of porcine SCNT embryos for 8 days and subsequent culture of the resulting porcine SCNT blastocysts on MEF feeder cells derived from outbred ICR mice. These findings represent an essential step toward the establishment of ESCs from porcine SCNT blastocyst.

\section{DISCUSSION}

Successful derivation of ESCs from porcine SCNT blastocysts depends on the quality of porcine SCNT blastocysts and the harmonization of cellular niche derived 

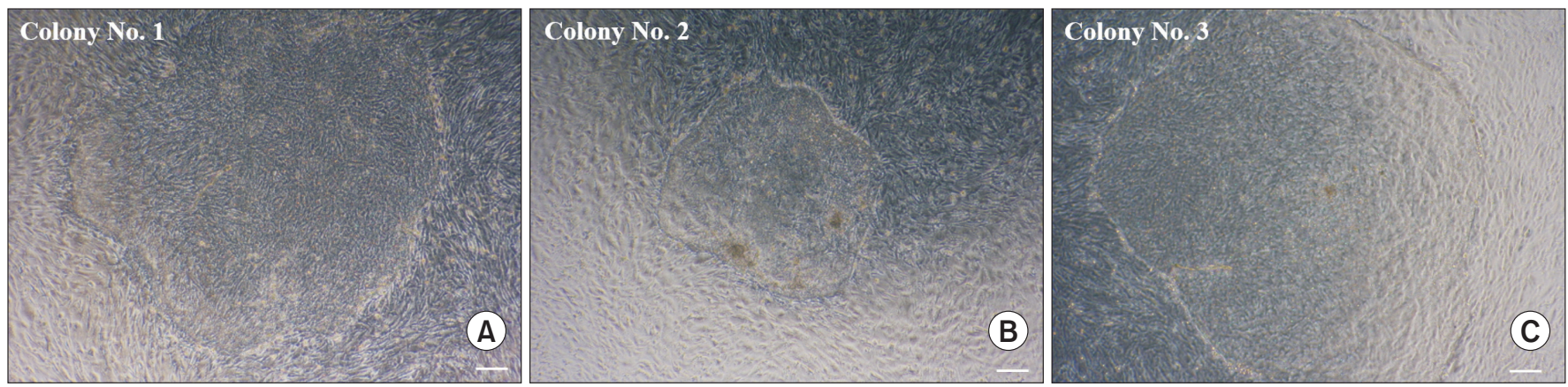

Fig. 1. Morphologies of in vitro maintained colonies over Passage 2 post-formation of colonies from inner cell mass (ICM) of blastocysts produced through in vitro culture of porcine somatic cell nuclear transfer (SCNT) embryos for 8 days. Blastocysts were generated through sequential culture of porcine SCNT embryos for $96 \mathrm{~h}$ in modified PZM-5 medium and for $96 \mathrm{~h}$ in PZM-5F. Zona pellucida-free porcine SCNT blastocysts were cultured for 7 days on mitotically inactivated mouse embryonic fibroblast (MEF) feeder cells derived from outbred ICR mice in $\alpha$-MEM-based medium. Outgrowth colonies were mechanically dissociated into several clumps, which were then cultured for 4 days in the mixture medium, and subculture was conducted under the same conditions. All colonies subcultured until Passage 2 showed well-defined boundaries and flattened morphology (A-C). Scale bar, $200 \mu \mathrm{m}$.

from feeder cells with ICM of porcine SCNT blastocysts. Therefore, we attempted to develop a culture technique for producing blastocysts with enhanced efficiency in the colony formation from reconstructed porcine SCNT embryos and determine the genetic origin of cellular niche stimulating formation and proliferation of colonies from ICM of porcine SCNT blastocysts. As the results, the best formation efficiency and maintenance of colonies were observed when porcine SCNT blastocysts produced in vitro for 8 days were cultured on cellular niche derived from outbred ICR MEFs. Accordingly, this study demonstrates that the quality of porcine SCNT blastocysts can be upgraded through in vitro culture for 8 days and the genetic origin of cellular niche supporting adaptation of ICM derived from porcine SCNT blastocysts to in-vitro environment is genetic background derived from outbred ICR mouse.

The number of cells in blastocysts affect not only embryo quality but also formation of colonies derived from ICM in the generation of ESCs. A previous study reported that lengthening the in vitro culture period of reconstructed embryo resulted in an increase in the total cell number of porcine SCNT blastocysts (Tan et al., 2012). In our results, formation efficiency of colonies derived from ICM was significantly enhanced in porcine SCNT blastocysts produced through in vitro culture of the reconstructed porcine SCNT embryos for 8 days, compared to those for 7 days (Table 1). Therefore, these improvement of efficiency in the formation of colonies from porcine SCNT blastocysts may result from higher total cell number of porcine SCNT blastocysts produced through in vitro embryo culture for 8 days than those for 7 days.

Generally, feeder cells regulate self-renewal of ESCs by secreting cytokines or unknown factors produced by feeder cells (Nii et al., 2014; Guo et al., 2018), which are transported by microtubules to extracellular fluid (Li et al., 2004). Thus, the status of microtubules in feeder cells can be used as a selective marker for quality of feeder cell. Previous research demonstrated that porcine embryonic fibroblast (PEFs) and MEF feeder cells increasing efficiency of attachment and colony formation in the establishment of ESCs from porcine blastocysts showed microtubules with long length, widespread distribution, and increased number, compared to STO feeder cells reducing efficiency of attachment and colony formation in the establishment of ESCs from porcine blastocysts (Li et al., 2004). As shown in Table 2 and Fig. 1, compared to MEF feeder cells from inbred C57BL/ 6 and hybrid B6CBAF1 mice, MEF feeder cells derived from outbred ICR mice showed higher attachment efficiency and colony formation, and stronger in vitro maintenance of colonies with typical porcine ESC morphology over Passage 2. Therefore, we suggest that the higher competence of MEF feeder cells derived from outbred ICR mice may result from strong or continuous secretion of cytokines or unknown factors which may result from microtubule characteristics including higher abundance, longer length, and more widespread distribution in the cytoplasm of ICR micederived MEF feeder cells.

In conclusion, as a step toward developing a novel sys- 
tem for ESC establishment, we developed a culture technique for producing blastocysts with enhanced efficiency in the colony formation from reconstructed porcine SCNT embryos and stimulating colony formation of ICM derived from porcine SCNT blastocysts. A combination of these techniques will contribute greatly to improving the efficiency of the establishment of ESCs derived from porcine SCNT blastocysts.

\section{CONFLICTS OF INTEREST}

No potential conflict of interest relevant to this article was reported.

\section{ACKNOWLEDGEMENTS}

This research was supported by Korea Institute of Planning and Evaluation for Technology in Food, Agriculture, Forestry and Fisheries (IPET) through Agri-Bioindustry Technology Development Program, funded by Ministry of Agriculture, Food and Rural Affairs (MAFRA) under Grant IPET 312060-05 and IPET 117042-3.

\section{AUTHOR CONTRIBUTIONS}

NRH and SB designed carried out most of the experiments in this research. YL and JL generated SCNT blastocysts. Moreover, JIY and EL analyzed and discussed the results. The manuscript was written by NRH and STL who supervised the research.

\section{AUTHOR'S POSITION AND ORCID NO.}

\author{
NR Han, Ph.D Student, \\ https://orcid.org/0000-0001-6279-5150 \\ $S$ Baek, Ph.D Student, \\ https://orcid.org/0000-0002-5839-1329 \\ Y Lee, Ph.D Student, \\ https://orcid.org/0000-0002-3723-4869 \\ J Lee, Ph.D., \\ https://orcid.org/0000-0001-7233-6409 \\ JI Yun, Ph.D., \\ https://orcid.org/0000-0001-9633-2947 \\ E Lee, Professor, \\ https://orcid.org/0000-0001-9654-7788 \\ ST Lee, Professor, \\ https://orcid.org/0000-0002-8952-3881
}

\section{REFERENCES}

Baek S, Han NR, Yun JI, Hwang JY, Kim M, Park CK, Lee E, Lee ST. 2017. Effects of culture dimensions on maintenance of porcine inner cell mass-derived cell self-renewal. Mol. Cells 40:117-122.

Brevini T, Pennarossa G, Maffei S, Gandolfi F. 2012. Pluripotency network in porcine embryos and derived cell lines. Reprod. Domest. Anim. 47 Suppl 4:86-91.

Brevini TA, Antonini S, Cillo F, Crestan M, Gandolfi F. 2007. Porcine embryonic stem cells: facts, challenges and hopes. Theriogenology 68 Suppl 1:S206-S213.

Cha HJ, Yun JI, Han NR, Kim HY, Baek S, Lee SH, Lee J, Lee E, Park CK, Lee ST. 2018. Generation of embryonic stem-like cells from in vivo-derived porcine blastocysts at a low concentration of basic fibroblast growth factor. Reprod. Domest. Anim. 53:176-185.

Chen LR, Shiue YL, Bertolini L, Medrano JF, BonDurant RH, Anderson GB. 1999. Establishment of pluripotent cell lines from porcine preimplantation embryos. Theriogenology 52:195-212.

Choi KH, Lee DK, Kim SW, Woo SH, Kim DY, Lee CK. 2019. Chemically defined media can maintain pig pluripotency network in vitro. Stem Cell Reports 13:221-234.

Guo R, Ye X, Yang J, Zhou Z, Tian C, Wang H, Wang H, Fu H, Liu C, Zeng M, Yang J, Liu L. 2018. Feeders facilitate telomere maintenance and chromosomal stability of embryonic stem cells. Nat. Commun. 9:2620.

Han NR, Baek S, Lee Y, Lee J, Yun JI, Lee E, Lee ST. 2019. Establishment of in-vitro culture system for enhancing production of somatic cell nuclear transfer (SCNT) blastocysts with high performance in the colony formation and formation of colonies derived from SCNT blastocysts in pigs. J. Anim. Reprod. Biotechnol. 34:130-138.

Haraguchi S, Kikuchi K, Nakai M, Tokunaga T. 2012. Establishment of self-renewing porcine embryonic stem cell-like cells by signal inhibition. J. Reprod. Dev. 58:707-716.

Hou DR, Jin Y, Nie XW, Zhang ML, Ta N, Zhao LH, Yang N, Chen Y, Wu ZQ, Jiang HB, Li YR, Sun QY, Dai YF, Li RF. 2016. Derivation of porcine embryonic stem-like cells from in vitro-produced blastocyst-stage embryos. Sci. Rep. 6:25838.

Kim E and Hyun SH. 2016. Apoptosis in porcine pluripotent cells: from ICM to iPSCs. Int. J. Mol. Sci. 17:E1533.

Lee J, Lee Y, Jung HH, Lee ST, Lee GS, Lee E. 2018. Effect of glycine and various osmolarities of culture medium on in vitro development of parthenogenesis and somatic cell nuclear transfer embryos in pigs. J. Emb. Trans. 33:221-228.

Li M, Ma W, Hou Y, Sun XF, Sun QY, Wang WH. 2004. Improved isolation and culture of embryonic stem cells from Chinese miniature pig. J. Reprod. Dev. 50:237-244.

Li P, Wang S, Zhan L, He X, Chi G, Lv S, Xu Z, Xia Y, Teng S, Li L, Li Y. 2017. Efficient feeder cells preparation system for largescale preparation and application of induced pluripotent stem cells. Sci. Rep. 7:12266.

Llames S, García-Pérez E, Meana Á, Larcher F, del Río M. 2015. 
Feeder layer cell actions and applications. Tissue. Eng. Part B Rev. 21:345-353.

Nakamura Y, Tajima S, Kikuchi K. 2017. The quality after culture in vitro or in vivo of porcine oocytes matured and fertilized in vitro and their ability to develop to term. Anim. Sci. J. 88:1916-1924.

Nii T, Marumoto T, Kawano H, Yamaguchi S, Liao J, Okada M, Sasaki E, Miura Y, Tani K. 2014. Analysis of essential pathways for self-renewal in common marmoset embryonic stem cells. FEBS Open Bio 4:213-219.

Park YG, Lee SE, Kim EY, Hyun H, Shin MY, Son YJ, Kim SY, Park SP. 2015. Effects of feeder cell types on culture of mouse embryonic stem cell in vitro. Dev. Reprod. 19:119-126.

Siriboon C, Lin YH, Kere M, Chen CD, Chen LR, Chen CH, Tu CF, Lo NW, Ju JC. 2015. Putative porcine embryonic stem cell lines derived from aggregated four-celled cloned embryos produced by oocyte bisection cloning. PLoS One 10:e0118165.

Son HY, Kim JE, Lee SG, Kim HS, Lee E, Park JK, Ka H, Kim HJ, Lee CK. 2009. Efficient derivation and long term maintenance of pluripotent porcine embryonic stem-like cells. Asian-Aust. J. Anim. Sci. 22:26-34.

Talbot NC, Sparks WO, Powell AM, Kahl S, Caperna TJ. 2012. Quantitative and semiquantitative immunoassay of growth factors and cytokines in the conditioned medium of STO and CF-1 mouse feeder cells. In Vitro Cell. Dev. Biol. Anim. 48:1-11.

Tan G, Ren L, Huang Y, Tang X, Zhou Y, Zhou Y, Li D, Song H, Ouyang H, Pang D. 2012. Isolation and culture of embryonic stem-like cells from pig nuclear transfer blastocysts of different days. Zygote 20:347-352.

Vackova I, Ungrova A, Lopes F. 2007. Putative embryonic stem cell lines from pig embryos. J. Reprod. Dev. 53:1137-1149.

Wianny F, Perreau C, Hochereau de Reviers MT. 1997. Proliferation and differentiation of porcine inner cell mass and epiblast in vitro. Biol. Reprod. 57:756-764.

Yamanaka K, Sugimura S, Wakai T, Kawahara M, Sato E. 2009. Difference in sensitivity to culture condition between in vitro fertilized and somatic cell nuclear transfer embryos in pigs. J. Reprod. Dev. 55:299-304.

Yang H, Qiu Y, Zeng X, Ding Y, Zeng J, Lu K, Li D. 2016. Effect of a feeder layer composed of mouse embryonic and human foreskin fibroblasts on the proliferation of human embryonic stem cells. Exp. Ther. Med. 11:2321-2328.

Zhang M, Wang C, Jiang H, Liu M, Yang N, Zhao L, Hou D, Jin Y, Chen Q, Chen Y, Wang J, Dai Y, Li R. 2019. Derivation of novel naive-like porcine embryonic stem cells by a reprogramming factor-assisted strategy. FASEB J. 33:9350-9361. 